\title{
MINERALOGY OF THE SAHARAN AEOLIAN DUST IN CRETE: EXAMPLES FROM THE PERIOD 2004-2009
}

\author{
Christidis, G.E. ${ }^{\mathbf{1}}$, Perdikatsis, $\mathrm{V}^{\mathbf{1}}$ and Apostolaki, $\mathrm{Ch}^{\mathbf{1}}$. \\ ${ }^{1}$ Technical University of Crete, Department of Mineral Resources Engineering, 73100 Chania, Greece, \\ vperdik@mred.tuc.gr,christid@mred.tuc.gr,xapostol@mred.tuc.gr
}

\begin{abstract}
Aeolian dust sediments, which were deposited by spring rainstorms or directly by the dust cloud were collected in the Technical University of Crete during the interval 2004-2009. The samples display remarkable mineralogical homogeneity and consist of illite, quartz, calcite, albite, kaolinite, palygorskite and dolomite. Chlorite or/and smectite is present in samples collected in 2006 and 2009. Gypsum is present in the collected from the airborne dust in 2009, but not from the sample which precipitated from rain in the same day. Mirabilite was traced in the sediment collected in 2005. The presence of palygorskite and dolomite in all samples and gypsum and mirabilite in two of the collected sediments implies formation of the original material in an arid environment characterized by alkaline $\mathrm{pH}$. The mineralogical composition coupled with back trajectory analysis on similar dust clouds indicate that the clouds originated in areas of Western Sahara or/and southern Morocco and that major mixing with fine-grained material from Europe is less probable. The possibility for a Central Algerian source for the airborne dust clouds is rejected because of the lack of smectite.
\end{abstract}

Key words: Airborne dust, Crete, Sahara, Sahel, palygorskite, illite, quartz, dolomite, arid alkaline environment.

\section{Introduction}

Every year, especially in spring and autumn Greece receives significant amounts of Aeolian dust from Africa. This phenomenon is widespread in all South European countries of the Mediterranean region (Bücher and Lucas, 1984). The dust clouds originate from the Sahara desert and are typically observed as yellowish-brown clouds that are washed out by rains mostly against topographic barriers, which cause uplift of the of the transporting air-masses (Prodi and Fea, 1979; Nihlen and Mattsson, 1989). It is interesting that dust clouds from the Sahara have been traced as far as north Europe namely Germany (Littmann and Steinrücke, 1989) and Scandinavia (Franzén, 1989) as well as in North and South American continent (Prospero, 1999; Stuut et al., 2009). Mineral dust aerosols from desert regions contribute significantly to the total atmospheric aerosol load (Linke et al., 2006). For this reason they have been studied considerably in various places in the world such as the Middle East (Abdul-Wahab et al., 2005) China (Yi et al., 2007).

An Aeolian dust system is described by particle formation (P), particle transportation (T) and particle deposition (D) events, known as the PTD scheme (Smalley et al., 2005). Particle formation events include both determination of the locality of and mechanisms of formation. Determination of the locality of formation is difficult because the exact transportation paths are often not known with cer- 


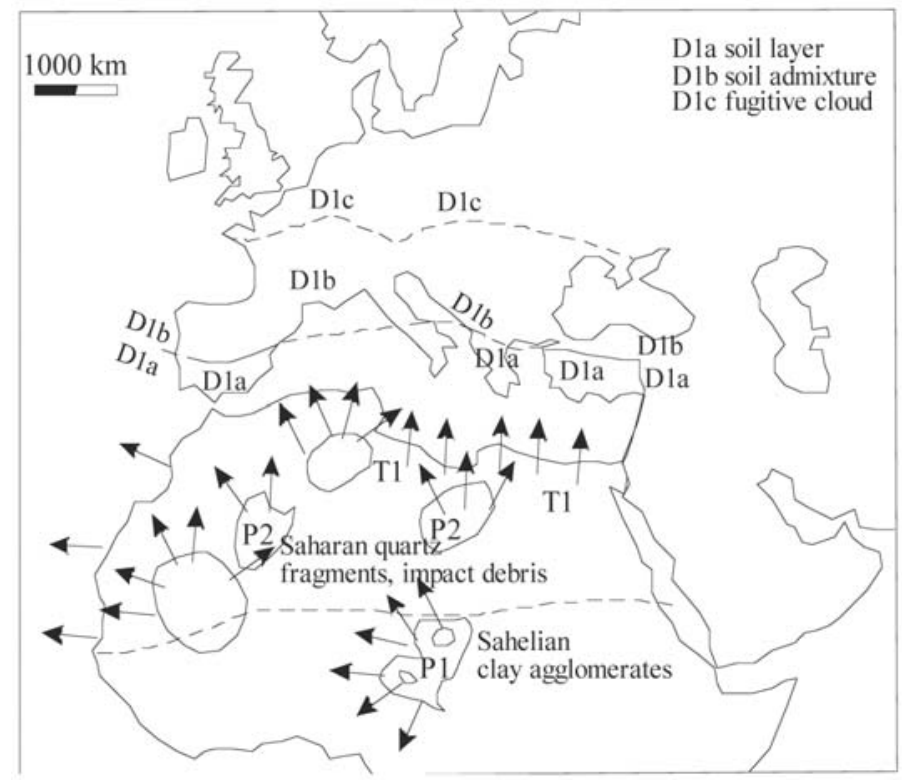

Fig. 1: Source areas and deposition sites of dust clouds, which originate in Saharan and Sahelian areas of North Africa. P denote particle formation areas, $\mathrm{T}$ denote transportation and $\mathrm{D}$ denote areas of deposition (modified from Stuut et al., 2009).

tainty and multiple sources are often involved in the formation of the cloud. More recently back trajectory analysis and direct satellite image data have been used to determine the sources of the Aeolian Saharan dust (Stuut et al., 2009). Notwithstanding the small deviations between the various authors there is general consent for the existence of a main source in Western Sahara including Morocco and Mauritania, and two additional sources, one in South Libya and Chad and one in Egypt and North Sudan (Fig. 1). The latter two sources located south of the $30^{\circ} \mathrm{N}$ can be classified as "Sahelian" (see below).

Due to the frequency of the Saharan airborne dusts over Greece including Crete, they have been studied extensively during the past few years. The studies are focused on the optical and physical properties of the airborne clouds (e.g. Fotiadi et al., 2006; Balis et al., 2006 among others). In contrast the mineralogical composition of the dusts has not been studied in the past. In this contribution we present the mineralogical composition of different airborne Saharan dusts which were deposited in the Technical University of Crete, Chania in spring time during the years 2004-2009. Moreover important conclusions about the type of the dust source (single over variable sources) are drawn.

\section{Types of Saharan airborne dust}

The Saharan dust has been classified according to its particle size into small dust and large dust (Livingstone and Warren, 1996). According to this classification scheme, large dust has coarse silt (16-31 $\mu \mathrm{m})$ and very coarse silt (31-63 $\mu \mathrm{m})$ size, it consists predominantly of quartz crystals and it travels short distances and forms loess deposits. Large dust deposits have been recognized in proximal deposition areas to Sahara such as Sicily, southern Italy and Crete (Corregiari et al., 1989; Guerzoni et al., 1996; di Sarra et al., 2002). Fossil large-dust deposits have also been recognized 
Table 1. Mineralogical composition of the airborne dust samples

\begin{tabular}{|c|c|c|c|c|c|c|c|c|c|c|}
\hline Sample & Quartz & Illite & Albite & $\begin{array}{c}\text { Kaolin- } \\
\text { ite }\end{array}$ & $\begin{array}{c}\text { Paly- } \\
\text { gorskite }\end{array}$ & $\begin{array}{c}\text { Dolomit } \\
\boldsymbol{e}\end{array}$ & Calcite & $\begin{array}{c}\text { Chlorite/ } \\
\text { smectite }\end{array}$ & Gypsum & TCM*** \\
\hline NLB 5_5_04R & 19.3 & 30 & 9.3 & 8.2 & 6.3 & 5.8 & 21.2 & - & - & 44.5 \\
\hline LB 17_4_05R* & 19 & 29.8 & 7.4 & 4.8 & 4.9 & 4.7 & 28.7 & - & - & 39.5 \\
\hline LB21_4_06R & 15 & 38.6 & 12 & 5.1 & 3.5 & 3.2 & 17 & 4.6 & - & 47.2 \\
\hline LB5_3_09R & 25.8 & 28.7 & 14 & 6.9 & 3.5 & 4.3 & 12.7 & 4.5 & - & 39.1 \\
\hline LB5_3_09D & 24.5 & 30 & 10 & 8 & 3 & 3.5 & 13 & 3 & 5 & 41 \\
\hline
\end{tabular}

*Sample LB17_4_05 contains traces of mirabilite $\left(\mathrm{Na}_{2} \mathrm{SO}_{4}\left(\mathrm{H}_{2} \mathrm{O}\right)_{10}\right)$

$* * \mathrm{TCM}=$ Total Clay Mineral content.

across the European continent. In contrast small dust deposits have been traced not only in central and northern Europe but in the American continent and the Middle East and Central Asia as well (Prospero, 1999).

Small dust includes both Saharan and Sahelian inputs (Stuut et al., 2009). The term Sahelian includes origin from basins in peri-Saharan areas, south of the $30^{\text {th }}$ parallel. Two main types of airborne particles have been recognized in small dust, clay mineral agglomerates (CMA) and monominerallic fragments, mainly quartz and feldspar. The CMA are in fact fine grained lake deposits, which consist of quasicrystals of different clay minerals. Several Sahelian basins have been considered as sources of fine dust, the most important being Lake Chad and areas of Western Sahara and southern Morocco. However, due to the complex trajectories of the dust clouds, which pass over extended Ergs (large desert areas consisting of sand dunes known as sea sands) most of them contain both large dust and small components, due to mixing.

\section{Sampling and experimental methods}

Five airborne dust samples were collected in canisters in spring of 2004, 2005, 2006 and 2009. The first 3 samples were deposited in the canisters by rain. In 2009 we collected two samples, one directly from the dust cloud and the second after rain the same day. Therefore these two samples represent materials which were transported with the same mechanism but were deposited via a different process. The samples are denoted according to the type of deposition (rain or cloud) and date of collection. For example LB5_5_04R indicates that the sample was collected in $5^{\text {th }}$ May 2004 after rain and LB5_3_09D denotes that the sample was collected in $5^{\text {th }}$ March 2009 from the dust cloud. Notation of the samples and sampling dates are listed in Table 1. The deposited dust clouds were collected the next day. The samples were filtered to remove rain water, dried at $105^{\circ} \mathrm{C}$ and stored in plastic bags.

Bulk mineralogy was determined by X-ray powder diffraction (PXRD) (Siemens D500, CuKa radiation, graphite monochromator, $35 \mathrm{kV}$ and $35 \mathrm{~mA}$, using a $0.02^{\circ}$ step size and 1 second per step counting time), on randomly oriented samples initially gently ground with pestle and mortar in acetone. Since all samples were mainly fine grained (fine dust samples) minimum grinding was applied. Quantitative analysis was carried out using Autoquan software using Rietveld refinement and standardless profile fitting. The relative error of the quantitative estimations is $\pm 5 \%$ for minerals present in amounts greater than $50 \%$ and $\pm 10 \%$ for minerals present in amounts less than $10 \%$. 


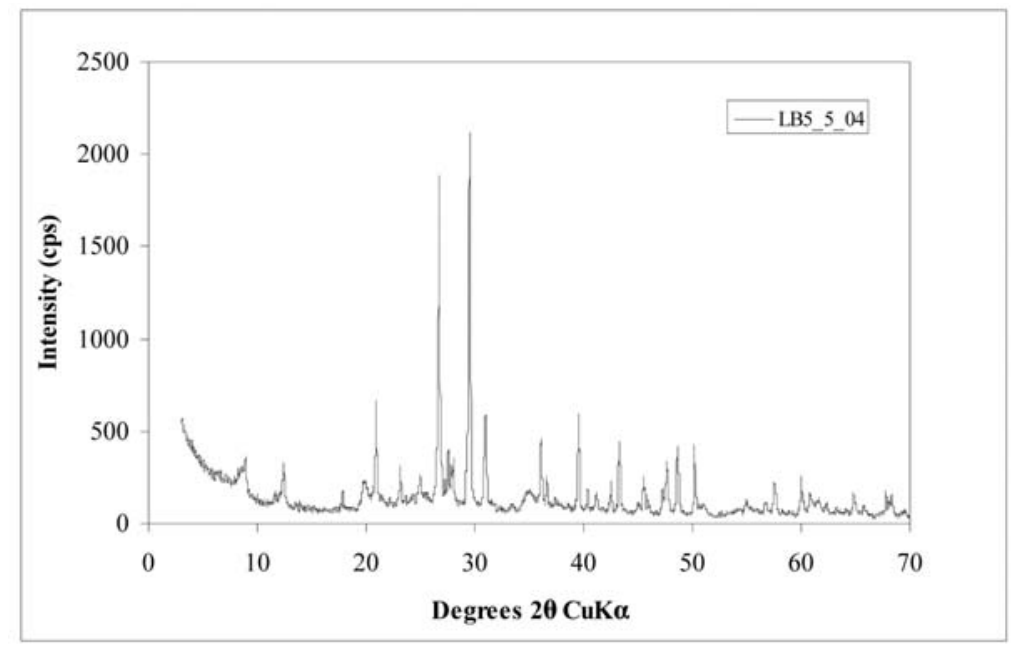

Fig. 2: Representative XRD of Aeolian dust sample LB_5_5_04.
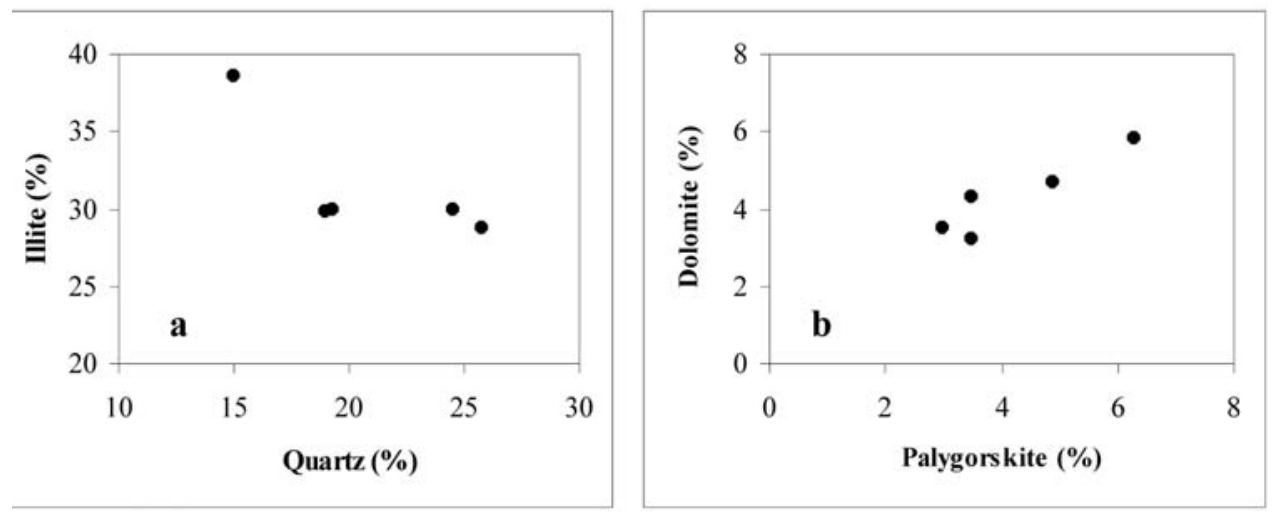

Fig. 3: Compositional trends in the Aeolian dust samples.

\section{Results}

The mineralogical composition of the samples is listed in Table 1. Representative XRD trace is shown in Figure 2. In general the composition of dust remains constant through time. The main change in the mineralogical composition is the decrease of carbonates and palygorskite and the increase of quartz content towards present. The most widespread phase is illite, the abundance of which remains essentially constant with time and so is the total clay mineral (CM) content. This is expected, because the clay fraction is dominated by illite. Kaolinite is the second most abundant clay minerals, whereas chlorite or/and smectite are present only in the samples from 2006 and 2009 sediments.

The mineralogical composition of samples displays certain mineralogical trends. A clear negative relationship holds between illite and quartz (Fig. 3a). Similar trend is observed between quartz and total clay mineral content (not shown). In contrast a distinct positive trend is observed between dolomite and palygorskite (Fig. 3b) and suggests a possible common origin of the two minerals. This is typ- 
ical of alkaline soils frequently found in arid areas, such as the Sahara desert. The composition of samples LB5_3_09R and LB5_3_09D is essentially identical except for the presence of gypsum in the latter (Table 1). The lack of gypsum from sample LB5_3_09R is attributed to the conditions of deposition of the two samples. Deposition from rain water dissolved the small amounts of gypsum initially present in the dust cloud. Dissolution took place in the canister, which was used to collect the samples, because gypsum was in contact with rain water for several hours before collection.

\section{Discussion}

The Aeolian dust sediments, which were collected over a period of 6 years, display remarkable compositional homogeneity both in terms of the type of minerals present and their abundances. This homogeneity reflects common source areas and transportation paths. The collected sediments have two major characteristics a) they are rich in clay minerals (39.1-47.2 wt \%) and b) they contain palygorskite. Potential sources of palygorskite are areas of Western Sahara and southern Morocco (Molinaroli, 1996). Although the northern sectors of Sahara are closer to Crete it seems that the Aeolian clouds follow a different route. The possibility for a source in the Western part of North Africa is supported by the back trajectory analysis of an Aeolian dust cloud, which was traced in August 2003 in northern and central Greece and Crete (Balis et al., 2006). This analysis clearly indicates a Western Saharan source for the cloud, which practically coincides with area P2 (Fig. 1), and trajectory route over Corsica, South Italy and Central Greece.

The well expressed positive relationship between palygorskite and dolomite implies a common origin for the two minerals. Mg-silicates and carbonates are common phases in soils formed in arid or semi-arid climates (Meunier, 2005). In such environments intense evaporation increases significantly the concentration of alkalis and alkaline-earth elements. Salts precipitate a precise soil levels controlled by capillary forces. Soils with crusts of salt or gypsum occur in schots or sahkhas. In such environments the $\mathrm{pH}$ is alkaline ( 9) favouring precipitation of palygorskite and dolomite. Mg-rich silicates in these environments form at the expense of detrital Al-rich phyllosilicates such as kaolinite, illite or smectite. Both illite and kaolinite, which can act as precursors of palygorskite are present in the samples. Moreover the presence of gypsum and mirabilite in two of the collected sediments strongly suggests an alkaline environment.

In general the presence of quartz, kaolinite dolomite and calcite is considered a good indication of Saharan origin (Chester et al., 1984; Avila et al., 1997). Also palygorskite has been considered as tracer of desert dust. With the exception of calcite, the abundances of these minerals are in accordance with their corresponding abundances in soils from the Moroccan Atlas and Western Sahara (Avila et al., 1997). Calcite is particularly enriched in the dust samples of the present study, although its abundance decreases towards present. This enrichment in calcite may indicate mixing with other soil source areas rich in this mineral. Note that calcite is not systematically related to the precipitation of palygorskite and this is indicated also in the data of our study (Table 1).

An important difference with previous studies on Aeolian dust samples which originated in the Western part of North Africa is the lack of smectite which is virtually absent from our samples or it may be present in trace amounts (Table 1). The reason for the lack of smectite is not known with the existing data. Note that all possible sources in the broader Western North Africa contain smectite, with Central Algeria being richer in this mineral (Avila et al., 1997). This suggests that the Central Algerian soils must be excluded as source materials for the Aeolian dusts. Finally, the lack of chlorite indicates that important mixing with other soils rich in this mineral, such as the Iberian soils (Avila et al., 1997) has not taken place. 


\section{Conclusions}

Aeolian dust sediments which were collected from Crete during spring storms in the interval 20042009 display remarkable mineralogical heterogeneity. They are rich in clay minerals and their origin must be sought for in the areas of Western Sahara and/or south Morocco. The lack of smectite from the samples precludes the possibility for origin from Central Algeria. The consistent mineralogical composition over this time interval suggests that the air circulation in the air which is responsible for the transportation of the dust clouds remain essentially unchanged during this time interval. Although mineralogy points towards certain origin for the dust clouds, the study should be complemented with back trajectory analysis, using weather data available for the periods of sampling for verification of the mineralogical data. This will be performed in the near future.

\section{References}

Abdul-Wahab, S.A., Worthing, M.A. \& Al-Maamari, S. 2005. Mineralogy of atmospheric suspended dust in three indoor and one outdoor location in Oman. Environ. Monitor. Assess., 107, 313-327.

Avila, A., Queralt-Mitjans, I. \& Alarcon, M. 1997. Mineralogical composition of African dust delivered by red rains over northeastern Spain. J. Geophys. Res. 102 (D18), 21977-21996.

Balis, D., Amiridis, V., Karadzis, S., Papayannis, A., Tsaknakis, G., Tzortzakis, S., Kalivitis, N., Vrekoussis, M., Kanakidou, M., Mihalopoulos, N., Chourdakis, G., Nickovic, S., Perez, C., Baldasano, J. \& Drakakis, M. 2006. Optical characteristics of desert dust over the East Mediterranean during summer: a case study. Ann. Geophys., 24, 807-821.

Bücher, A. \& Lucas, G. 1984. Sedimentation eolienne intercontinentale, poussieres sahariennes et geologie. Bull. Centres Res. Explor.-Production ELF Aquitaine, 8, 151-165.

Chester, R., Sharples, E.J., Sanders, G.S. \& Saydam, A.C. 1984. Saharan dust incursion over the Tyrrhenian Sea. Atmos. Environ. J, 18, 929-935.

Corregiari, A., Guerzoni, L., Lenaz, R., Quarantotto, G. \& Rampazzo, G. 1989. Dust deposition in the central Mediterranean (Tyrrhenian and Adriatic Seas): relationships with marine sediments and riverine input. Terra Nova, 1, 549-558.

di Sarra, A., Cacciani, M., Chamard, P., Cornwall, C., DeLuisi, J J., Iorio di T., Disterhoft, P., Fiocco, G., Fua, D., Monteleone, F. 2002. Effects of desert dust and ozone on the ultraviolet irradiance at the Mediterranean island of Lambedusa during PAUR II. J. Geophys. Res., 107 (D18), 8135.

Evans, R.D., Jefferson, I.F., Kumar, R., O'Hara-Dhand, K. \& Smalley, I.J. 2004. The nature and early history of airborne dust from North Africa; in particular the Lake Chad basin. J. Afr. Earth Sci., 39, 81-87.

Fotiadi, A., Hatzianastassiou, N., Drakakis, M., Matsoukas, C., Pavlakis, K.G., Hatzidimitriou, D., Gerasopoulos, E., Mihalopoulos, N. \& Vardavas, I. 2006. Aerosol physical and optical properties in the Eastern Mediterranean Basin, Crete, from Aerosol Robotic Network data. Atmos. Chem. Phys., 6, 5399-5413.

Franzén, L.G. 1989. A dustfall episode on the Swedish West Coast, October 1987. Geogr. Ann. Ser. A, Phys. Geog., 71, 263-267.

Guerzoni, S., Quarantotto, G., Cesari, G., Molinaroli, E., Rampazzo, G. \& Le Balloch, O. 1996. Trace metal composition and grain size of the particulates in aerosols and precipitation collected in NW Mediterranean $\left(39^{\circ} \mathrm{N}, 9^{\circ} \mathrm{E}\right)$ a multivariate analysis. In: Guerzoni, S. \& Chester, R (eds), The impact of Desert Dust Across the Mediterranean. Kluwer Academic Publishers, Rotterdam, 333-338.

Linke, C., Möhler, O., Veres, A., Moracsi, A., Bozoki, Z., Szabo, G \& Schnaiter, M. 2006. Optival properties and mineralogical composition of different Saharan mineral dust samples: a laboratory study. Atmos. Chem. Phys. Discuss., 6, 2897-2922. 
Littmann, T. \& Steinrücke, J. 1989. Atmospheric boundary conditions of recent Saharan dust influx into Central Europe. GeoJournal, 18, 399-406.

Livingstone, I. \& Warren A. 1996. Aeolian Geomorphology: An introduction. Longman, London, 211 p. Meunier, A. 2005. Clays. Springer-Verlag, Berlin, 472p.

Molinaroli, E. 1996. Mineralogical characterization of Saharan dust with a view to its final destination in Mediterranean sediments. In: Guerzoni S. \& Chester, R. (eds) The impact of Desert Dust Across the Mediterranean. Kluwer, Rotterdam, 153-162.

Nihlen, T. \& Mattsson, J.O. 1989. Studies on eolian dust in Greece. Geogr. Ann., 71A, 269-274.

Prodi, F. \& Fea, G. 1979. A case of transport and deposition of Saharan dust over the Italian peninsula and southern Europe. J. Geophys. Res., 84 (C11), 6951-6960.

Prospero, J.M. 1999. Long-range transport of mineral dust in the global atmosphere: Impact of African dust on the environment of the southeastern United States. Proc. Natl.Acad.ScI. USA., 96, 3396-3403.

Smalley, I.J., Kumar, R., O’Hara-Dhand, K., Jefferson, I.F. \& Evans, R.D. 2005. The formation of silt material for terrestrial sediments; particularly loess and dust. Sed. Geol., 179, 321-328.

Stuut, J-B., Smalley, I. \& O’Hara-Dhand, K. 2009. Aeolian dust in Europe: African sources and European deposits. Quatern. Inter., 198, 234-245.

Yi., S.L., Li, W.J., Yang, S.S., Shi, Z.B. \& Lü, S.L. 2007. Mineralogical characteristics of airborne particles collected in Beijing during a severe Asian storm period in spring 2002. Sci. China Ser. D-Earth Sci., 50, 953-959. 